\title{
The Roadmap: a blueprint for evidence literacy within a Scientifically Informed Medical Practice and Learning Model
}

\author{
Suzana Alves Silva MD PhDa and Peter C Wyer MD \\ a Clinical Research Manager, PROCEP Centro de Ensino e Pesquisa, Rio de Janeiro, Brazil \\ b Associate Clinical Professor of Medicine, Columbia University College of Physicians and Surgeons, New York City, NY, \\ USA
}

\begin{abstract}
Background: A model of clinical practice that encompasses clinical relationships and choices as well as the use of clinical research has yet to be elaborated. We sought a model for Scientifically Informed Medical Practice and Learning (SIMPLE) through integrating concepts borrowed from narrative medicine with the results of a competency-based assessment project. Methods: The SIMPLE model started by subordinating the cognitive skills within an information literacy model ('ask', 'acquire', 'appraise' and 'apply') to the content of clinical actions ('therapy', 'diagnosis', 'prognosis' and 'harm'). This enabled a description of problem delineation. The content of these components was developed through an iterative, reflexive approach, elaborating distinctions across all action domains. This led to the "Road Map" component of the model. Clinical action domains were defined within a relational construct.

Results: We define 3 sub-categories of Problem (utility, performance and likelihood) leading to shared Actions, Choices and Targets (PACT) within the SIMPLE model as a bridge between relational and information literacy fields. The enabling skill 'ask' and the "Patients, Interventions, Comparisons, Outcomes” (PICO) format, are applied uniformly across these categories. 'Acquire' is elaborated using a 3-S format (Summaries, Syntheses, Single studies) that links study designs to electronic sources (published synopses, filtered databases and large bibliographical databases). 'Appraise' involves evaluation of design-specific susceptibility to error and of importance of the results. The latter are classified as measures of frequency, effect, impact and precision. Finally, 'apply' includes assessment of directness of evidence, contextual issues and overall benefits versus risks. Translation of knowledge into action involves constructed priorities and preferences within the relational field.

Conclusion: The Road Map enables linkage of a broad range of patient and practitioner concerns related to clinical action to a comparably broad spectrum of contemporary clinical research. It may usefully guide curricular and instructional approaches. Empirical validation in improving learning outcomes is required.
\end{abstract}

\section{Keywords}

Clinical action, clinical encounter, clinical knowledge, clinical skills, evidence-based medicine, information literacy, limitations, medical education, practice guidelines, randomised trials

\section{Correspondence address}

Dr. Peter Wyer, 446 Pelhamdale Avenue, Pelham, NY 10803, USA. E-mail: pwyer@att.net

Accepted for publication: 20 April 2012

\section{Background}

“Evidence-based medicine” (EBM), first defined in 1991 [1] and elaborated in 1992 [2], proposed integration of clinical research evidence with patient perspectives and practitioner expertise. It drew concepts from biomedical informatics [3] and clinical epidemiology [4]. Originally aimed at the training of physicians, the term is currently understood as applying to all allied healthcare disciplines. EBM offers skills aimed at bringing information from clinical research to bear on clinical practice [5] and has developed critically important concepts and resources relevant to this achievement. However, there are important limitations of EBM as elaborated to date. These include restriction to a narrow range of clinical questions that can be addressed and the research designs that can be considered in relationship to those questions [6,7]. For example, questions of therapy conventionally are referred to information from randomized trials [7]. Diagnostic questions are confined to issues of accuracy (performance) of diagnostic tests rather than issues of clinical benefit (utility) of diagnostic strategies [7]. Limiting EBM instruction to a narrow range of questions may prevent learners from using EBM to solve problems arising from their own clinical experience. 


\section{Box 1 Explanation of terms and categories used in the text}

\begin{tabular}{|l|l|}
\hline Term or Phrase & Explanation \\
\hline Information Literacy & $\begin{array}{l}\text { The critical access, evaluation and use of information from electronic resources in response to problem solving } \\
\text { needs. In this article it largely refers to critical use of information from clinical research using competencies } \\
\text { commonly categorized as "Ask", "Acquire", "Appraise" and "Apply". }\end{array}$ \\
\hline Utility & $\begin{array}{l}\text { The magnitude of observable patient benefit resulting from clinical actions pertaining to therapy, diagnosis, } \\
\text { prognosis or harm. }\end{array}$ \\
\hline Performance & $\begin{array}{l}\text { The accuracy of patient characteristics, tests or other instruments in predicting the probability of outcomes } \\
\text { associated with therapy, diagnosis, prognosis or harm. }\end{array}$ \\
\hline Likelihood & The simple probability of outcomes associated with therapy, diagnosis, prognosis or harm. \\
\hline Summaries & Designs and sources that address research on multiple questions related to a specific clinical topic. \\
\hline Syntheses & Designs and sources that encompass results of multiple studies pertaining to a single clinical question. \\
\hline Single studies & Designs and sources that report information from a single data set pertaining to a single clinical question. \\
\hline Synopses & $\begin{array}{l}\text { A type of source that provides short, independently appraised, digests of information aimed at facilitating use } \\
\text { by busy clinicians and managers. Synopses pertain to summaries, syntheses and single studies. }\end{array}$ \\
\hline Frequency & Measures expressed as simple proportions, such as risk of an outcome of a single patient or group of patients. \\
\hline Effect & $\begin{array}{l}\text { Measures pertaining to the effect of an intervention, exposure or assessment on the likelihood of an outcome. } \\
\text { Such measures characteristically pertain to a broad range of patients at varying risk of the outcome in } \\
\text { question. }\end{array}$ \\
\hline Impact & $\begin{array}{l}\text { Measurements pertaining to the magnitude of the effect of an intervention, exposure or assessment on the } \\
\text { likelihood of an outcome for an individual patient. }\end{array}$ \\
\hline Precision & $\begin{array}{l}\text { The range of values around a measure of outcome within which the true value probably resides, } \\
\text { notwithstanding the possible effect of systematic error. }\end{array}$ \\
\hline
\end{tabular}

Perhaps the most important limitation of much of the EBM literature is the avoidance of the task of connecting actual clinical encounters to information needs. Clinical questions, rather than problems, are the starting point and in many cases are derived from research studies rather than from actual clinical cases [8]. A frequently cited guide for evidence-based curriculum development [9] limits itself to information literacy skills [10,11] (asking questions, acquiring, appraising and applying research evidence to practice) ignoring consideration of the clinical actions that give rise to information needs. The terms therapy, diagnosis, prognosis and harm do not appear in that guideline [9].

EBM defines skill sets conforming to 4 information literacy categories, ask, acquire, appraise and apply (see Box 1). Our experience of teaching EBM in concentrated settings such as workshops led to the perception that many learners become confused and disoriented because they do not understand the relationship of each of these categories to the process of improving care through consideration of clinical research. Elwyn et al surveyed tutors at well known EBM workshops and observed substantial confusion among tutors and participants regarding the overall learning goals [12]. Wyer et al found that the graduates of such workshops were unable to identify questions requiring the use of EBM skills in response to simulated clinical encounters [13]. A model that helps learners to remedy these deficiencies requires that the interpretive world of clinical practice be explicitly connected to the world of information [14].

To address these limitations, we developed a model for Scientifically Informed Medical Practice and Learning (SIMPLE) [14]. We previously described the model as a whole which subordinates information literacy to the interactive, relational aspects of patient care drawing from elaborated principles of narrative medicine [14]. In this article we present the EBM or information literacy [10], component of the model, hereafter referred to as the "Road Map.”

\section{Methods}

\section{Model development}

A project to elaborate tools for assessment of the EBM related cognitive skills encompassed within the US Accreditation Council on Graduate Medical Education's description of competency in practice based learning and improvement served as the point of departure for developing the SIMPLE model [15]. The project concluded that 4 domains of clinical action (therapy, diagnosis, prognosis, harm) govern the EBM skill content within the information literacy field (ask, acquire, appraise, apply). (Figures $1 \mathrm{a}$ and $1 \mathrm{~b}$ ). It further provided provisional, non-overlapping, definitions for the component skills within the information literacy field across all these 4 action domains.

The SIMPLE model expanded the aforementioned definitions of clinical action and placed them within a relational field distinct from the information literacy field within which EBM resides [7]. Problem categories were further differentiated into "utility", "performance" and "likelihood" and the concept of problem delineation was introduced. Finally, drawing on principles of narrative medicine and social constructivism, we defined PACT ('Problem delineation', 'Action', 'Choices' and 'Targets') 


\section{Figure 1 Original derivation of the Skill Map - For explanation, see text}

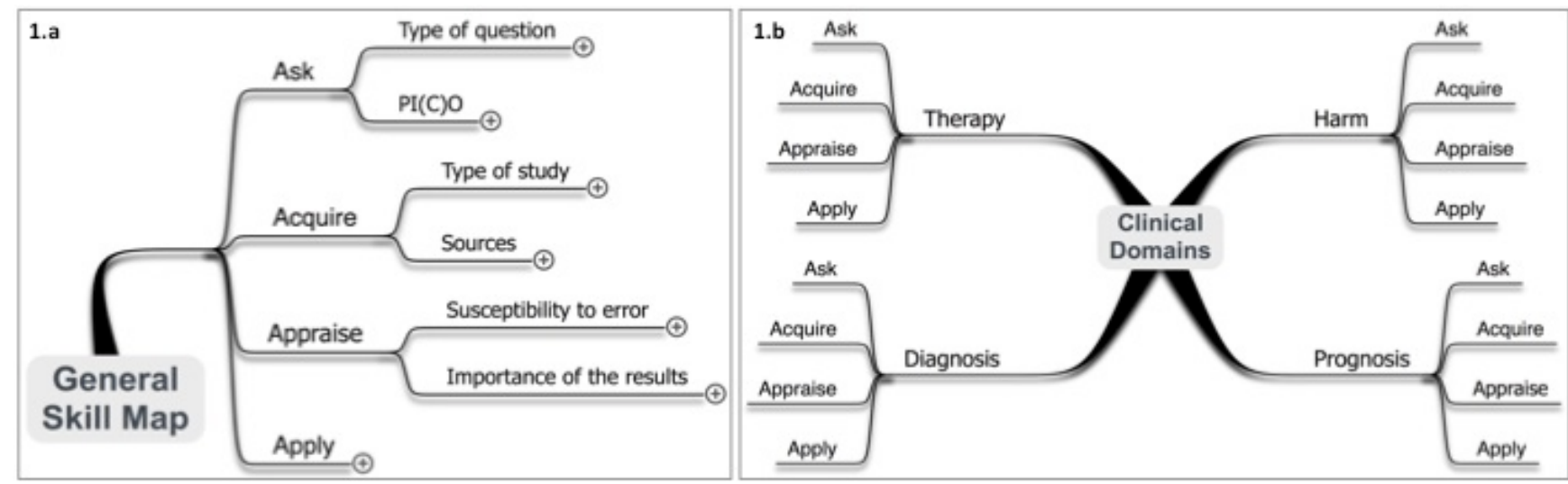

Figure 2 The Skill Map: a differentiated form of the information literacy skills. For explanation, see text

\begin{tabular}{|c|c|c|c|}
\hline Clinical Actions & Skills & Competencies & Distinctions \\
\hline \multirow{20}{*}{$\begin{array}{l}\text { Therapy } \\
\text { Diagnosis } \\
\text { Prognosis } \\
\text { Ham }\end{array}$} & Ask & Identify the Target & $\rightarrow$ Utility \\
\hline & & & $\rightarrow$ Performance \\
\hline & & & $\rightarrow$ Likelihood \\
\hline & & Build a structured question & $\rightarrow \mathrm{PICO}$ \\
\hline & Acquire & Identify the type of information & $\rightarrow$ Summaties \\
\hline & & & $\rightarrow$ Syntheses \\
\hline & & & $\rightarrow$ Single studies \\
\hline & & Identify the source & $\rightarrow$ Synopses \\
\hline & & & $\rightarrow$ Filtered Databases \\
\hline & & & $\rightarrow$ Large Biomedical Databases \\
\hline & & Build the search strategy & \\
\hline & Appraise & Validity & $\rightarrow$ B eginning-Middle-End \\
\hline & & Importance of the results & $\rightarrow$ Impact-Effect-Frequency \\
\hline & & & $\rightarrow$ Precision \\
\hline & Apply & Ass...................... & $\rightarrow$ PICO Research \\
\hline & & & $\rightarrow$ PICO Practice \\
\hline & & Consider practice and patient & $\rightarrow$ Quality Perfomance Measures \\
\hline & & circumstances and feasibility & $\rightarrow$ Costs \\
\hline & & Consider scientific knowledge & $\rightarrow$ Risks \\
\hline & & beyond immediate evidence & $\rightarrow$ Benefits \\
\hline
\end{tabular}

as a conceptual tool for recognizing and delineating clinical problems and their relationship to information needs [14]. PACT, as elaborated previously [14], may also be used to delineate differences between patient and practitioner perspectives and priorities and help guarantee that the clinical questions arising from a clinical encounter reflect the concerns of both practitioners and patients. PACT ultimately facilitates the identification and review of research literature relevant to the problem as constructed [16] by patient and practitioner [14].

The aforementioned measurement project [15] developed specifications for the practice based learning/EBM domain by identifying skills within the information literacy categories: ask; acquire; appraise and apply and by elaborating those skills across all domains and subdomains. We extended and continued this process in developing the SIMPLE model and the Road Map 
within it. For example, we determined that the concepts of utility, performance and likelihood (see Box 1) apply to all 4 clinical actions (therapy, diagnosis, prognosis and harm). Under acquire, we found that search targets are best differentiated into sources and designs and further subdivided into 3 hierarchical levels: summaries; syntheses and single studies (see Box 1). Similarly, under appraisal, following a temporal principle, first introduced as a vehicle for understanding the critical appraisal of randomized trials [17], we described all research designs using a 'beginning', 'middle' and 'end' conceptual subdivision. Finally, the presentation of results was classified using 4 categories of relevance: measures of frequency; effect; impact and precision (Box 1).

\section{Results}

\section{The Road Map to evidence literacy and assimilation}

The Road Map to evidence literacy, described in this article, is one component of a larger model described previously [14]. Within this model, the world of research information is subordinated to a relational field within which the 4 classes of interaction, therapy, diagnosis, prognosis and harm (TDPH) are defined. The reader is referred to a previous publication that describes the relational dimension of the SIMPLE model in detail [14].

The augmented skill tree illustrated in Figure 2 reflects the results of the process of elaboration and differentiation of the EBM skills, ask, acquire, appraise and apply, within the framework of the SIMPLE model. Table 1 presents the expanded definitions of these 4 action classes (TDPH), each subdivided into 3 categories of clinical problem: likelihood, performance and utility (see Box 1). Once the problem is appropriately understood and patient and practitioner priorities weighted, then specific questions may be derived in such a way as to enable effective identification and evaluation of potentially useful research evidence.

In the following section we will first describe the content of the EBM skill categories derived from information literacy within the model. We will then address some of the implications of the approach with respect to curricular and instructional design.

\section{The skill categories}

The following summary of the skills within the Road Map follows the scheme presented in Figure 2. It reflects a conceptual order defined by the information literacy construct [11]. It should not be interpreted to define the actual chronology of cognitive tasks within clinical problem solving. For example, "apply" skills are elaborated as the $4^{\text {th }}$ category, even though they begin to operate as soon as a clinician initiates development and formulation of a clinical question (“ask”).

\section{Ask}

Literacy in 'ask' related skills enables a clinician to derive questions corresponding to the 3 subcategories of problems: utility, performance and likelihood, within the categories therapy, diagnosis, prognosis and harm and to structure them using the Patients, Interventions, Comparisons, Outcomes (PICO) format. Questions derived from all of these subcategories of problems may lead to useful published research.

\section{Identify the Target}

'Utility' questions are familiar in the context of the effect of therapeutic interventions on patient important outcomes. However, they pertain to diagnostic $[18,19]$ and prognostic [20] issues as well. For example, the presence or absence of patient benefit resulting from counseling regarding genetic susceptibility to Alzheimer's disease was recently assessed in a randomized trial [20].

'Performance' is a familiar concept insofar as it relates to the accuracy of diagnostic tests and assessments and also that of prognostic predictors and prediction instruments. It also relates to issues of therapy and harm, for example, the ability to predict the probability that an individual patient will benefit from therapy constitutes a major focus of the human genome project [21]. One older study reported the use of the head upright tilt test to predict response to beta-blockers among patients with recurrent vasovagal syncope [22]. Similarly, the ability to predict susceptibility to intracranial hemorrhage caused by thrombolytic therapy administered to patients with ischemic stroke has been a focus of controversy in the literature [23].

'Likelihood' is familiar to most readers in the context of prognosis questions and also in relationship to diagnostic outcomes such as studies of differential diagnosis [24]. Likelihood is also important in the context of therapy and harm. For example, strong inferences regarding the safety of electrical conversion and outpatient management of patients presenting to emergency departments with paroxysmal atrial fibrillation were drawn from the results of a single arm trial [25], that is, the absence of adverse outcomes among patients receiving the intervention was taken as evidence supporting such a clinical option. In the field of quality improvement, inferences are characteristically made out of local outcome measures, for example, the rate of catheter and mechanical ventilation related infection as markers of good care. Questions under the category of likelihood are frequently issues of priority for patients and payers who are anchored in local practice and want to be certain about the quality of care delivered, as, for example, the likelihood of events if submitted to a certain intervention in that specific setting [26]. 
Table 1 PACT Table of Definitions

PACT: P: Problem delineation; A: Actions; C: Choices; T: Targets LPU: L: Likelihood; P: Performance; U: Utility

\begin{tabular}{|c|c|c|c|c|c|}
\hline & $P$ & \multirow[b]{4}{*}{$\begin{array}{l}\frac{n}{0} \\
\frac{0}{0} \\
\frac{0}{0}\end{array}$} & \multirow{2}{*}{$\begin{array}{cc}\text { A } \\
\text { Share consideration of what would happen } \\
\text { if submitted to a therapeutic intervention: } \\
\vec{\rightarrow} & \text { Clinical } \\
\rightarrow & \text { Surgical } \\
\rightarrow & \text { Preventive }\end{array}$} & \multirow{2}{*}{$\frac{\mathrm{C}}{\text { No relevant choices }}$} & $\mathrm{T}$ \\
\hline \multirow{3}{*}{ 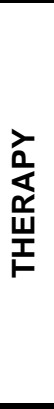 } & $\mathbf{L}$ & & & & $\begin{array}{l}\text { Estimate of likelihood of important } \\
\text { outcomes attributable to the disease, } \\
\text { condition or injury }\end{array}$ \\
\hline & $\mathbf{P}$ & & $\begin{array}{l}\text { Share consideration of the performance of a } \\
\text { predictor or rule to predict response to a } \\
\text { therapeutic intervention }\end{array}$ & No relevant choices & $\begin{array}{l}\text { Estimate of effect of presence of } \\
\text { predictors or rule on the likelihood of } \\
\text { important outcomes }\end{array}$ \\
\hline & $\mathbf{U}$ & & $\begin{array}{l}\text { Share consideration of a therapeutic } \\
\text { intervention }\end{array}$ & $\begin{array}{l}\text { Share consideration of } \\
\text { alternative or standard } \\
\text { treatments }\end{array}$ & $\begin{array}{l}\text { Estimate of magnitude of effect on } \\
\text { important outcomes attributable to the } \\
\text { disease, condition or injury }\end{array}$ \\
\hline \multirow{3}{*}{ 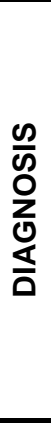 } & $\mathbf{L}$ & \multirow{3}{*}{ 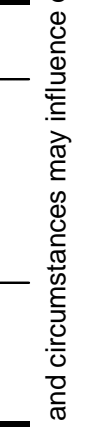 } & $\begin{array}{l}\text { Share consideration of a set of signs and } \\
\text { symptoms }\end{array}$ & No relevant choices & $\begin{array}{l}\text { Estimate of likelihood of possible } \\
\text { diagnoses }\end{array}$ \\
\hline & - & & 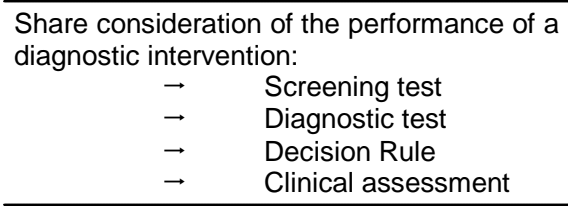 & $\begin{array}{l}\text { Share consideration of a } \\
\text { criterion assessment }\end{array}$ & $\begin{array}{l}\text { Estimate of effect of test, rule or } \\
\text { assessment on patient's likelihood of } \\
\text { the disease, condition or injury }\end{array}$ \\
\hline & - & & $\begin{array}{l}\text { Share consideration of the utility of a } \\
\text { diagnostic intervention }\end{array}$ & $\begin{array}{l}\text { Share consideration of } \\
\text { alternative assessments }\end{array}$ & $\begin{array}{l}\text { Estimate of magnitude of effect on } \\
\text { important outcomes attributable either } \\
\text { to the disease, condition or injury or to } \\
\text { the process of care }\end{array}$ \\
\hline \multirow{3}{*}{ 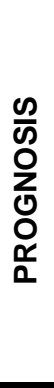 } & $\mathbf{L}$ & 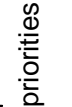 & $\begin{array}{l}\text { Share consideration of clinical outcomes } \\
\text { over a predefined period of time }\end{array}$ & No relevant choices & $\begin{array}{l}\text { Estimate of likelihood of important } \\
\text { outcomes attributable to the disease, } \\
\text { condition or injury }\end{array}$ \\
\hline & $\mathbf{P}$ & 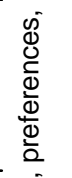 & 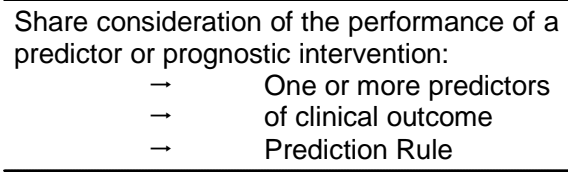 & No relevant choices & $\begin{array}{l}\text { Estimate of effect of presence of one } \\
\text { or more predictors on the likelihood of } \\
\text { important outcomes }\end{array}$ \\
\hline & $\mathbf{U}$ & $\frac{\stackrel{\infty}{0}}{\frac{D}{\sigma}}$ & $\begin{array}{l}\text { Share consideration of the utility of clinical } \\
\text { use of prognostic information }\end{array}$ & $\begin{array}{l}\text { Share consideration of } \\
\text { alternatives or standard } \\
\text { practice }\end{array}$ & $\begin{array}{l}\text { Estimate of the magnitude of effect of } \\
\text { clinical use or sharing of prognostic } \\
\text { information on important outcomes }\end{array}$ \\
\hline \multirow{6}{*}{$\sum_{\substack{\text { r } \\
\text { I }}}$} & \multirow[t]{2}{*}{$\mathbf{L}$} & 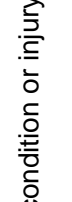 & \begin{tabular}{rc}
\multicolumn{3}{l}{ Share consideration of what would happen } \\
if accidentally & submitted to a harmful \\
intervention: & \\
$\rightarrow$ & Therapeutic \\
$\rightarrow$ & Diagnostic \\
$\rightarrow$ & Prognostic \\
\end{tabular} & No relevant choices & $\begin{array}{l}\text { Estimate of likelihood of important } \\
\text { adverse outcomes attributable to the } \\
\text { clinical intervention but not to the } \\
\text { disease, condition or injury that led to } \\
\text { the intervention }\end{array}$ \\
\hline & & 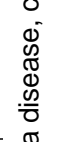 & 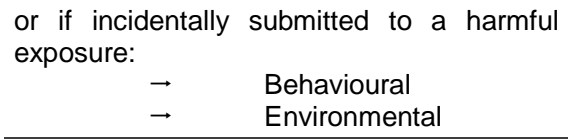 & No relevant choices & $\begin{array}{l}\text { or attributable to a behavioural or } \\
\text { environmental exposure }\end{array}$ \\
\hline & $\mathbf{P}$ & 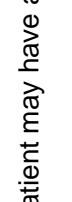 & \multicolumn{2}{|c|}{$\begin{array}{l}\text { Share consideration of the performance of a No relevant choices } \\
\text { predictor or rule to predict response to a } \\
\text { harmful intervention }\end{array}$} & $\begin{array}{l}\text { Estimate of effect of presence of } \\
\text { predictors or rule on the likelihood of } \\
\text { important adverse outcomes } \\
\text { attributable to the clinical intervention } \\
\text { but not to the disease, condition or } \\
\text { injury that led to the intervention }\end{array}$ \\
\hline & & 0 & or to an harmful exposure & No relevant choices & $\begin{array}{l}\text { or attributable to the environmental or } \\
\text { behavioural exposure }\end{array}$ \\
\hline & $\mathbf{U}$ & & $\begin{array}{l}\text { Share consideration of an accidental harm } \\
\text { due to a harmful intervention }\end{array}$ & $\begin{array}{l}\text { Share consideration of } \\
\text { alternative or standard } \\
\text { interventions }\end{array}$ & $\begin{array}{l}\text { Estimate of magnitude of effect on } \\
\text { important adverse outcomes } \\
\text { attributable to the clinical intervention } \\
\text { but not to the disease, condition or } \\
\text { injury that led to the intervention }\end{array}$ \\
\hline & & & $\begin{array}{l}\text { or incidental harm due to an incidental } \\
\text { exposure }\end{array}$ & $\begin{array}{l}\text { Share consideration of } \\
\text { alternative choices } \\
\text { exposures }\end{array}$ & $\begin{array}{l}\text { or attributable to the behavioural or } \\
\text { environmental exposure }\end{array}$ \\
\hline
\end{tabular}




\section{Build a Structured Question}

Turning to the final skill within the 'ask' category, the Road Map provides for a uniform and standardized use of the 'patients', 'interventions', 'comparisons' and 'outcomes' (PICO) scheme for formatting clinical questions preparatory to embarking on the 'acquire' tasks. The reader may visit www.ebcp.com.br/roadmap/pico for a set of examples of the use of the PICO format in connection with most types of clinical question.

\section{Acquire}

Literacy in 'acquire' related skills enables a clinician to connect a clinical question, according to its subcategory (likelihood, performance or utility), to a range of potentially relevant research designs and electronic sources and to construct search strategies for locating the most relevant information within those sources. Achievement of proficiency in this skill area requires an understanding of both the distinctions and relationships between research designs, electronic sources and the process of information integration.

\section{Identify the Types of Information and Design}

Research designs are categorized as "summaries", "syntheses" and "single studies" (see Box 1).This allows a well-defined conceptual framework for understanding the relationship among these designs. Single studies, for example, serve as 'building blocks' (Figure 3) for the more complex designs. Syntheses integrate the results of single studies on a single question. They follow a research design and are supported by abundant methodological literature that establishes standards irrespective of venue of publication. Summaries address multiple questions pertaining to a designated practice area and similarly may qualify as designs. Practice guidelines, for example, are subject to published methodological standards that are independent of venue of dissemination. Figure 4 illustrates the relationship of the question subtypes within therapy, diagnosis, prognosis and harm to the research designs conforming to summaries, syntheses and single studies.

\section{Identify the Source}

Figure 5 presents a 3 dimensional ' 3 -S' system (summaries, syntheses, studies) hierarchically organized according to descending complexity of these 3 different types of information available in the literature. For each level in the figure a corresponding hierarchy of study designs in one side and electronic sources in the other side is identifiable. Designs range from randomized and nonrandomized single studies to syntheses and summaries of such 'building block' studies of varying degrees of complexity. Sources range from large bibliographical databases such as MEDLINE, through filtered sources of primary reports, to 'synopsized' or pre-appraised, sources of information conforming to the underlying designs. This hierarchy of sources within each level of the pyramid follows a principle of descending degree of efficiency or 'user-friendliness'. For example, synopses of summaries, such as the National Guidelines Clearinghouse, may offer a condensed overview of methods and recommendations pertaining to a multiplicity of questions considered by a practice guideline in a fashion that is user friendly. This constitutes a higher degree of independent evaluation than that to be found within a practice guideline located in large databases such as MEDLINE.

The pyramid lists frequently encountered examples of source at every level. Hence, the Cochrane Central Registry ("Cochrane Central") is a filtered database of controlled trials, including trials reported in abstract only, while DARE (Database of Abstracts of Reviews of Effectiveness) constitutes a source of synopses (independently performed critical appraisals and commentaries) of systematic reviews.

The 3-S pyramid is designed to allow learners to quickly grasp the relationship between the categories of research design pertaining to clinical questions and electronic sources designed to expedite access. It is based on the recognition of common epidemiological principles underlying how such sources have been developed in tandem with the corresponding designs. However, the critical user of research also needs to understand principles of integration of information that underlie the development of searchable electronic resources and larger information systems.

Figure 6 illustrates how successive degrees of integration of information pertain to systems level applications of evidence-based information tools. On the level of integration of information, systems, within a specific practice setting, potentially encompass all levels and hierarchies of design and source. They dynamically and interactively build access to information drawn from research and from independent knowledge of disease process, all integrated with practice-specific information and the medical records pertaining to individual patients. To be able to use such a system critically, the evidenceliterate clinician must understand the nature and limitations of the ingredients that feed it, from the level of research design to the process through which research and also practice-specific information, is synthesized and digested.

\section{Build the Search Strategy}

The final component skill within the 'acquire' category is the ability to search the electronic resources selected in connection with a clinical question. We regard this as a 'performance-based' skill [27]. That is, it is dependent on a multiplicity of factors, including the size of the database and the estimated amount of relevant research to be found. The Road Map model has little to offer in the way of illuminating the content of electronic searching skills that has not been published elsewhere [28].

\section{Appraise}

Literacy in 'appraise' related skills enables a clinician to evaluate the susceptibility of research findings to design- 
related error and to understand the frequency, effect, impact and precision of the results (See Box 1). Critical evaluation of the quality and importance of information, such as information from research, is an established component of 'information literacy' and is crucial to the process of informing clinical practice through research. In contrast to conventional presentations of EBM [29], but in accordance with the principles of information literacy from which the definition of EBM skills arose [11], the model classifies 'apply' skills into a separate category. Such skills involve integrating information from research with prior medical knowledge and with knowledge of patient and practice circumstances.

\section{Validity}

The Road Map defines “designs” as reflecting a temporal process characterized by 'beginning', 'middle' and 'end' phases (Figure 3). This allows the learner to understand the process of selection of subjects, their linkage to interventions and observations, the critical evaluation of systematic flaws in design and execution of a study and the assessment of its results, all as aspects of a single conceptual framework. The first aspect of design has already been addressed above under acquire. The second constitutes what is otherwise commonly referred to as appraisal of internal validity.

Figure 3 illustrates how the 4 primary 'building block' designs used in clinical research (randomized trials, cohort studies, cross sectional studies and case-control studies) can be conceptualized using the 'beginning-middle-end' sequence. The 'beginning' phase defines patient selection and allocation; the 'middle' phase, the process of following and assessing them, with or without an intervention and the 'end' phase, the process of analysing the results. The scheme corresponds to a chronology of conceptual design rather than of data collection and hence allows elaboration of the essential similarities and differences between designs, irrespective of whether they are conducted retrospectively or prospectively.

Figure 3 also illustrates the categories of designspecific error in relationship to the 3 temporal phases. The 'beginning-middle-end' framework applies to complex designs such as systematic reviews as well as to the 'building block' designs (Table 2). The criteria used in the Road Map to evaluate validity of specific designs are otherwise similar to those used in the Users' Guides to the Medical Literature series [29].

\section{Importance of the Results}

The Road Map classification of outcome measures into results pertaining to frequency measurements (absolute risks, pre-test probabilities), effect (likelihood ratios, odds ratios, relative risks, hazard ratios) and impact (risk differences, numbers needed to treat and post-test probabilities) is aimed at facilitating their interpretation. The categories 'frequency', 'effect' and 'impact' do not strictly conform to the categories of 'likelihood', 'performance' and 'utility', but rather to the relationship of results of research to the implications for the individual patient. For example, for a study of performance of a diagnostic test, the sensitivity and specificity of a test and the likelihood ratio of a test result, constitute properties of the test, compared to a criterion standard assessment, which have different impact on patients and populations of different pre-test probability. Post-test probability is a direct measure of such impact. For studies of utility of therapeutic interventions, relative risks and odds ratios constitute properties of the intervention, compared to alternative treatments, which have different impact on patients and populations based on their baseline risk of clinical outcomes. Risk difference and number needed to treat are direct measures of such impact. Table 3 illustrates a number of the relationships between different subcategories of results and the 4 classes of clinical interaction and also the common relevance of issues of precision to the entire matrix.

\section{Apply}

Literacy in 'apply' related skills enables a clinician, firstly, to assess the similarity between the populations, interventions, comparisons and outcomes within relevant clinical research and the corresponding elements within the practice question; secondly, to consider the impact of patient and practice circumstances including culture, available resources and measures of local performance and, thirdly, to evaluate the potential risks and benefits of the choices being considered. As noted at the outset, "apply" skills begin to operate as soon as clinical questions are formulated and searches are planned. Their placement as the $4^{\text {th }}$ information literacy category does not reflect the actual time sequence of cognitive tasks.

\section{Assess Similarity of PICOs}

In the first step, once research evidence has been gathered and evaluated in relationship to a focused clinical question, the Road Map calls for a systematic comparison of the PICO elements of the clinical question to the corresponding elements within relevant research (see Figure 7). The patient characteristics of the practice PICO are compared to the characteristics of the subjects actually enrolled in the study. Similarly, the interventions (assessments or exposures), comparisons and outcomes as prescribed by the practice PICO are compared to those as actually performed in the research. Knowledge of disease process and pathophysiology informs the assessments that go into the '2-PICO' comparison. Important differences between practice and research PICO elements constitute potential sources of systematic error. The magnitude and direction of such error may or may not be predictable and may or may not be correctable. For example, likelihood ratios may be used to generate a more appropriate estimate of post-test probability for a patient or practice population than the predictive values reported in diagnostic performance studies [30]. 
Figure 5 The Pyramid: A 3 dimensional '3-S' hierarchical model linking research designs to electronic sources. For explanation, see text

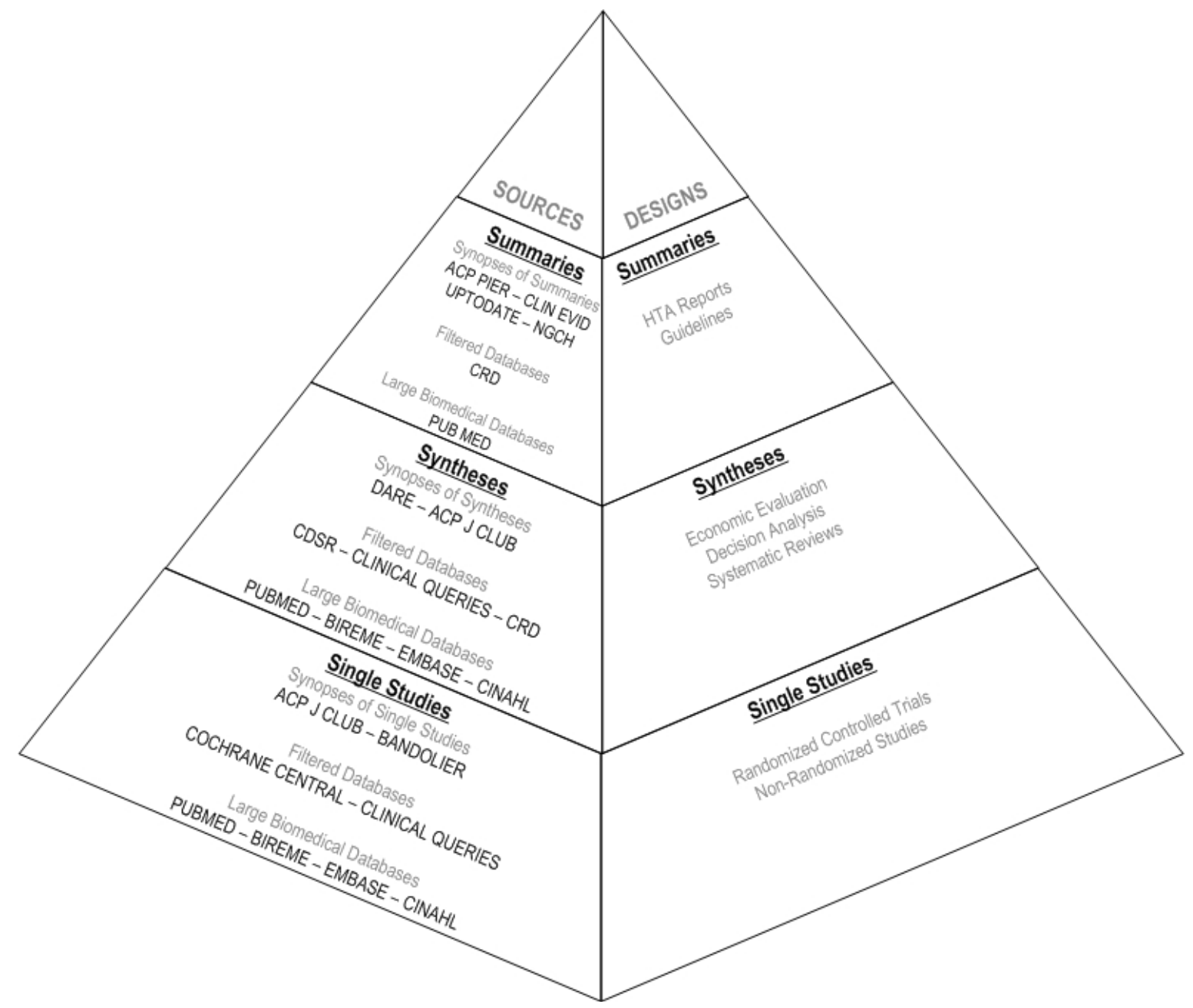

\section{Consider Practice and Patient Circumstances}

Moving to the second step, assessing the applicability of research evidence to practice requires consideration of the circumstances within which healthcare choices are to be made. Cost, availability of resources, insurance, patient economic status and issues to do with the healthcare system and its management are relevant here. The existence of established clinical policy, including performance quality measures, is considered. Many healthcare choices cannot be undertaken without systems level preparation. For example, the individual practitioner cannot be expected to prescribe thrombolytic therapy to a patient with ischemic stroke unless there is a corresponding policy within an accessible hospital service. If local performance respecting surgical options for a particular condition lags behind an acceptable standard, it may be inappropriate to recommend it, irrespective of the strength of supporting research evidence.

\section{Consider Other Scientific Knowledge}

The third step, assessing the overall risks and benefits of healthcare choices, requires consideration of independent scientific knowledge. Such knowledge also impacts on assessment of the scientific plausibility of research findings. Clinical research generally addresses a single focused question. The potential value of such research therefore depends on factors that go beyond the specific inquiry [31]. Full consideration of the potential harms of therapeutic or diagnostic options will frequently call for evaluation of scientific evidence independent of the evidence for benefit [32]. Hence, separate clinical queries, leading to different searches and to different types of studies, may be called for.

Two clarifications may help to put the 3 steps of the apply component of the Road Map summarized above into an appropriate perspective within the SIMPLE model. Firstly, the steps just described are not, in practice, confined to a single phase of the information literacy cycle. Rather they operate at all phases, including defining and 
Figure 6 Integration of information leading to systems level applications of evidence-based information tools. For explanation, see text

\begin{tabular}{|c|c|c|c|}
\hline Clinical Actions & $\begin{array}{l}\text { Levels of } \\
\text { Integration }\end{array}$ & Types of Sources & T ypes of Designs \\
\hline \multirow{9}{*}{$\begin{array}{l}\text { Therapy } \\
\text { Diagnosis } \\
\text { Prognosis } \\
\text { Harm }\end{array}$} & Systems & & \\
\hline & $\begin{array}{l}\text { Irtegration of sciertific } \\
\text { information with practice } \\
\text { systems }\end{array}$ & $\begin{array}{l}\rightarrow \text { Computed Decision Support } \\
\text { Systems with alert links to } \\
\text { medical records }\end{array}$ & \\
\hline & Summaries & & $\begin{array}{l}\rightarrow \text { Summaries } \\
\rightarrow \text { Syntheses } \\
\rightarrow \quad \text { Studies }\end{array}$ \\
\hline & $\begin{array}{l}\text { Multiple questions with or } \\
\text { without integration with } \\
\text { background knowledge, } \\
\text { values and preferences }\end{array}$ & $\begin{array}{l}\rightarrow \text { Synopses } \\
\rightarrow \text { Filtered Databases } \\
\rightarrow \quad \text { Large Biomedical Databases }\end{array}$ & \\
\hline & & $\begin{array}{l}\text { Symopes: } \mathrm{AGC} \text {, U ptodate, } \mathrm{ACP} \text { Piex } \\
\text { Filtered Datab ases: CRD } \\
\text { Large Databases: Fub med, Emb se, Bireme }\end{array}$ & $\begin{array}{l}\rightarrow \quad \text { Guidelines } \\
\rightarrow \quad \text { Health Technology } \\
\text { Assessment }\end{array}$ \\
\hline & Syntheses & & \\
\hline & $\begin{array}{l}\text { Single structured questions } \\
\text { on multiple studies }\end{array}$ & 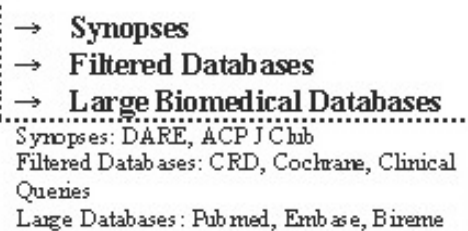 & $\begin{array}{l}\rightarrow \text { Decision Aralysis } \\
\rightarrow \text { Economic Analysis } \\
\rightarrow \text { Systematic Reviews }\end{array}$ \\
\hline & Studies & & \\
\hline & $\begin{array}{l}\text { Single stmetured question } \\
\text { on a single dataset }\end{array}$ & 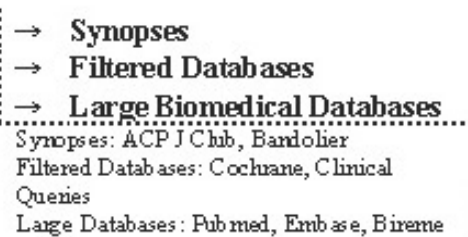 & $\begin{array}{ll}\rightarrow & \text { Randomized Trials } \\
& \text { Non Randomized } \\
& \text { Studies }\end{array}$ \\
\hline
\end{tabular}

formulating the question, selecting evidence from electronic searches and evaluating magnitude and precision of research results. Secondly, these aspects of applying research evidence to practice reside within the information literacy field of the SIMPLE model. They are extensions of the process of defining information needs and finding and evaluating information relevant to the satisfaction of those needs. In the course of the 'apply' phase, research information becomes integrated with the other sources of information and with underlying knowledge of disease. Hence, it is here that the first transformation of information into knowledge takes place.

However, the SIMPLE model also recognizes that the process of assimilating research evidence into practice involves another level of transformation, from knowledge as knowable by an individual practitioner to knowledge for action. The latter transformation takes place within the relational field of the model [14] and involves a process that Epstein calls constructed priorities and preferences [16]. The model recognizes that the relational dimension involves processes that cannot be reduced to simple processing of information. Furthermore, many categories of informational inputs pertain to clinical actions and choices that are not encompassed by the categories of clinical research embraced by the information literacy field of the SIMPLE model [33].

\section{Potential impact of road map in teaching}

The emphasis within the SIMPLE model on problem delineation, combined with its ability to embrace the full spectrum of clinical research, has made possible an important shift in approach to teaching of EBP in workshops and other settings. Rather than working from prepared critical appraisal packages built around a narrow selection of study designs, learners use actual patient experiences. The model allows consideration of the process through which the clinical problem was understood and interpreted by both patients and practitioners. The selection of the most important question to refer to relevant research evidence may change as a result.

The case of a stable elderly woman presenting to an emergency room with recurrent acute onset atrial fibrillation was considered in one workshop. The practitioners had focused on the choice of drugs for either rhythm or rate control and a literature search had uncovered several relevant systematic reviews of drug trials [34,35]. Reconsideration of the case in the EBP workshop setting led to recognition that the patient and 
Table 2 'Beginning-middle-end' framework to evaluate design specific error

\begin{tabular}{|c|c|c|c|}
\hline \multirow[t]{2}{*}{ Type of Study } & \multicolumn{3}{|c|}{ Criterion to Evaluate Bias } \\
\hline & Beginning & Middle & End \\
\hline Randomized Trial & $\begin{array}{l}\text { Randomization Allocation } \\
\text { concealment } \\
\text { Balanced prognostic factors }\end{array}$ & $\begin{array}{l}\text { Extent of blinding } \\
\text { Balanced co-intervention } \\
\text { Adequacy of assessment }\end{array}$ & $\begin{array}{l}\text { Loss to follow up } \\
\text { Intention to treat } \\
\text { Stopped early for benefit }\end{array}$ \\
\hline Cohort & Similarity of prognosis & $\begin{array}{l}\text { Frequency of assessment } \\
\text { Objective outcomes measures }\end{array}$ & $\begin{array}{l}\text { Loss to follow up } \\
\text { Adjustment for imba } \\
\text { prognostic factors }\end{array}$ \\
\hline Case-Control & $\begin{array}{l}\text { Prognostically similar groups with } \\
\text { equal opportunity of exposure }\end{array}$ & $\begin{array}{l}\text { Frequency of assessment } \\
\text { Equal and objective assessment } \\
\text { of exposure }\end{array}$ & $\begin{array}{l}\text { Adjustment for } \\
\text { prognostic factors }\end{array}$ \\
\hline Cross-Sectional & $\begin{array}{l}\text { Appropriate source and spectrum of } \\
\text { patients for research question }\end{array}$ & $\begin{array}{l}\text { Appropriate and independent } \\
\text { criterion standard } \\
\text { Adequacy of assessment }\end{array}$ & Blinding \\
\hline Systematic Review & $\begin{array}{l}\text { Compatibility of PICO elements and } \\
\text { designs across included studies }\end{array}$ & $\begin{array}{l}\text { Reproducible search, selection, } \\
\text { quality assessment and data } \\
\text { collection }\end{array}$ & Similarity of results (heterogeneity) \\
\hline
\end{tabular}

family values, as well as the prior experience of the patient with similar episodes, had been ignored. The family had advised: "shock (electrically cardiovert) her, the drugs never work" and expressed the desire to take her home after successful cardioversion. Once the problem was redefined as one of safety, a new literature search uncovered a single arm Canadian study that supported the family's preference [25]. The Road Map model allowed recognition of the study as corresponding to a "harm-likelihood" question, a category not conventionally included in the EBM teaching portfolio. The emphasis on problem delineation concretized the consideration of patient values and preferences into the exercise and the PACT tool facilitated the translation of the change in perspective (from therapy to harm) in a fashion that increased the potential value of relevant research to the resolution of the case. Table 4 (Concerns through designs) illustrates in a more systematic way how the Road Map approach results in a broad interface between shared patient and practitioner, concerns and an expanded range of clinical research.

The Road Map provides a general orientation regarding objectives and priorities of learner directed educational experiences related to EBM. At the outset of a workshop, participants sometimes express an almost exclusive interest in learning critical appraisal of specific study designs. When the Road Map is used to provide an overview of the skill areas, the emphasis broadens to encompass a balance across the skill sets represented in Figure 2. In other words, the Road Map helps to ensure that the learning choices made by individuals and groups in the course of time constrained experiences are informed choices. It similarly facilitates quick and efficient review of the content areas that have been covered both during and at the conclusion of such experiences.

The Road Map facilitates an orderly and systematic approach to potentially complex clinical problems. A Brazilian health manager with a background in cardiology brought a problem to a workshop involving use of the CHADAS score [36] to identify patients with chronic atrial fibrillation unlikely to benefit from anticoagulation. The
CHADAS score predicts stroke outcomes in such patients. The participant defined her problem in terms of the educational process involved in implementing use of the score for this purpose in her facility. Several studies of different design were located in searches. The Road Map facilitated distinguishing between performance studies of accuracy of the prediction rule [36] and prognostic utility studies in which impact of using the rule on patient important outcomes was assessed [37]. The Road Map, which avoids folding different types of utility issue into a generic category of "management", helped clarify that accuracy of the prediction rule and applicability to her patient care setting was the issue on which to initially focus. This required careful attention to issues of validity and applicability of studies of prognostic performance and likelihood.

\section{Disc ussion}

The SIMPLE model draws from concepts developed within narrative medicine. These help to illuminate how clinical problems are recognized and defined in a relational context, independent of the process of pursuing information needs from a practitioner perspective [14]. The Road Map, presented in this paper, elaborates the content of information literacy with respect to maximizing the value and use of information from clinical research in the care of individual patients.

The Road Map recognizes an expanded spectrum of clinical research relevant to each category of clinical action. This may address criticisms that EBM only applies to a narrow range of clinical practice, that is, therapy issues amenable to study via randomized trials [7]. The Road Map furthermore integrates complex designs, including systematic reviews, clinical prediction rules, decision analyses and practice guidelines, into a common field governed by the classes of clinical action. The SIMPLE 
Table 3 Relationships between sub-categories of results, study design and domains of clinical actions

\begin{tabular}{|c|c|c|c|c|c|}
\hline & & Therapy & Diagnosis & Prognosis & Harm \\
\hline \multirow{3}{*}{$\begin{array}{l}\text { Randomized } \\
\text { Trial }\end{array}$} & Frequency & & & & \\
\hline & Effect & $\mathrm{RR}, \mathrm{HR}, \mathrm{OR}$ & $\mathrm{RR}, \mathrm{HR}, \mathrm{OR}$ & $\mathrm{RR}, \mathrm{HR}, \mathrm{OR}$ & $\mathrm{RR}, \mathrm{HR}, \mathrm{OR}$ \\
\hline & Impact & $\mathrm{RD}$ & RD & $\mathrm{RD}$ & RD \\
\hline \multirow[t]{3}{*}{ Cohort } & Frequency & Risks & Risks & Risks & Risks \\
\hline & Effect & $\mathrm{RR}, \mathrm{HR}, \mathrm{OR}$ & $\mathrm{RR}, \mathrm{HR}, \mathrm{OR}$ & $\mathrm{RR}, \mathrm{HR}, \mathrm{OR}$ & $\mathrm{RR}, \mathrm{HR}, \mathrm{OR}$ \\
\hline & Impact & RD & $\mathrm{RD}$ & $\mathrm{RD}$ & $\mathrm{RD}$ \\
\hline \multirow[t]{3}{*}{ Case-Control } & Frequency & & & & \\
\hline & Effect & OR & LR, OR & OR & OR \\
\hline & Impact & & & & \\
\hline \multirow[t]{3}{*}{ Cross-Sectional } & Frequency & & Pre-test prob & & \\
\hline & Effect & & LR & & \\
\hline & Impact & & Pos-test prob & & \\
\hline All & Precision & $\mathrm{Cl}$ & $\mathrm{Cl}$ & $\mathrm{Cl}$ & $\mathrm{Cl}$ \\
\hline
\end{tabular}

CI: Confidence Interval; HR: Hazard Ratio; LR: Likelihood Ratio; OR: Odds ratio; RD: Risk Difference; RR: Relative Risk

Figure 7 The 2 PICOs comparison. For explanation, see text

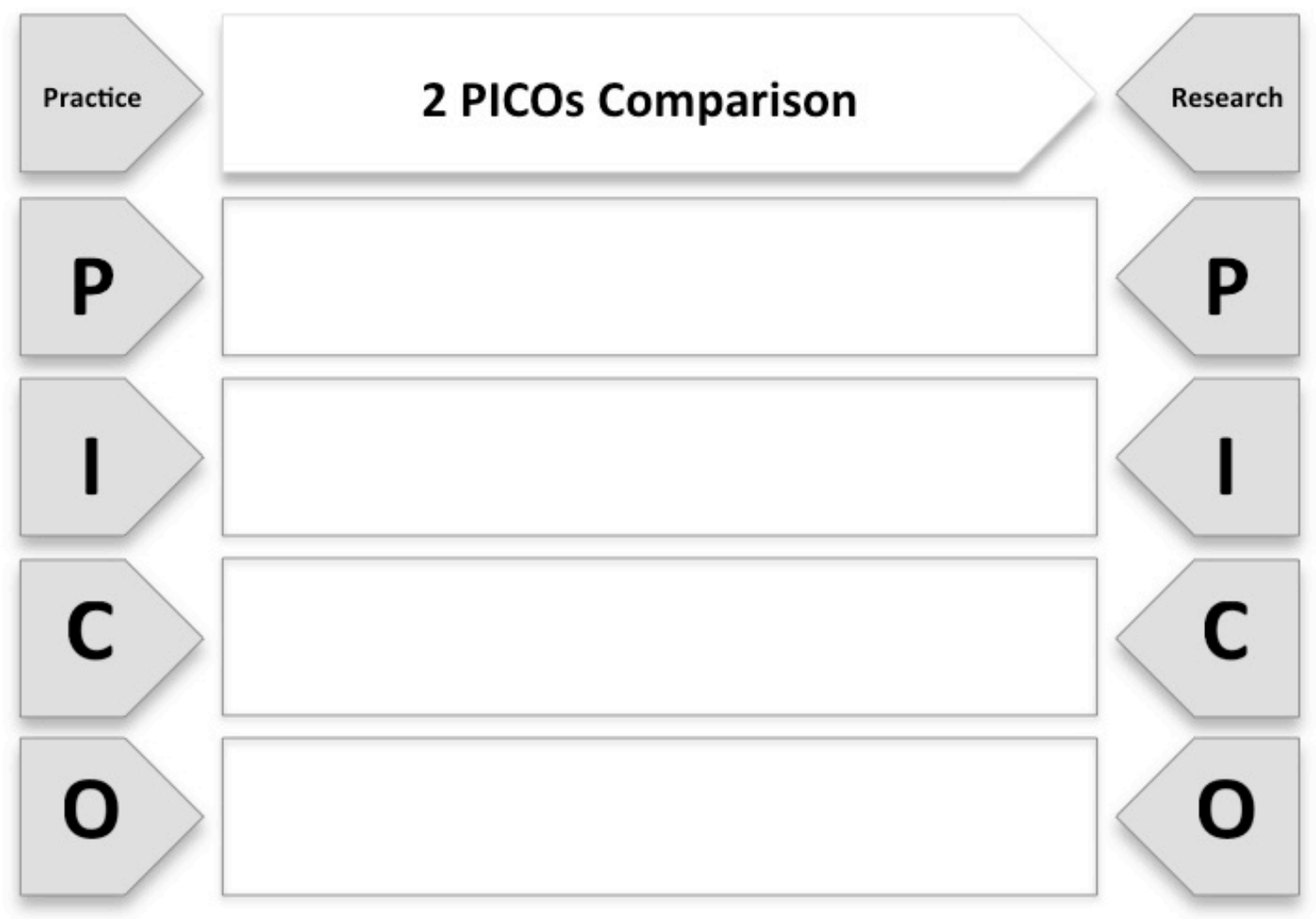

model and the Road Map within it, draws on the rigor of epidemiological concepts and corresponding information tools. However, these tools serve and enrich rather than dictate the content of clinical practice and decisions. This contrasts with other published models of evidence-based medicine [38].

The Road Map embraces frontier concepts within today's healthcare environment in a fashion that enhances curricular design. For example, the concept of diagnostic utility and corresponding research, elaborated by Sackett [18] and more recently in the literature on the Grading Recommendations Assessment, Development, and Evaluation (GRADE) system [19], is rarely emphasized in the standard instructional sources on EBM. The Road Map incorporates this concept in a fashion that renders it consistent with the corresponding concepts within therapy, prognosis and harm. Similarly, the '2-PICO' approach to applicability assessment (Figure 7) corresponds to the concept of 'indirectness' of evidence within the GRADE system [39,40]. This alignment constitutes a potential remedy to another important criticism of EBM, the failure to elaborate an educational framework that includes evidence-based guidelines together with evidence-based individual decision-making [41]. These concepts and principles can be routinely incorporated into curricula at all levels of training. 
Table 4 Concerns through designs. For explanation, see text

\begin{tabular}{|c|c|c|c|c|c|c|}
\hline \multirow[t]{2}{*}{ Action Class } & \multirow[t]{2}{*}{ Patient Concern } & \multirow[t]{2}{*}{ Question Subcategory } & \multicolumn{4}{|c|}{ Range of Building Block Designs* } \\
\hline & & & $\mathbf{R}$ & Co & CS & $\mathrm{CC}$ \\
\hline \multirow[t]{3}{*}{ Therapy } & "Will I feel better with this treatment?" & Utility & $\sqrt{ }$ & $\sqrt{ }$ & & $\sqrt{ }$ \\
\hline & $\begin{array}{l}\text { "Do I have a better than average chance } \\
\text { of benefiting from this treatment?" }\end{array}$ & Performance & $\sqrt{+}$ & $\sqrt{ }$ & & $\sqrt{ }$ \\
\hline & $\begin{array}{l}\text { "If I take this invasive treatment am I going } \\
\text { to die anyway?" }\end{array}$ & Frequency & $\sqrt{+}$ & $\sqrt{ }$ & & \\
\hline \multirow[t]{3}{*}{ Diagnosis } & "Will I live longer if I have this test?" & Utility & $\sqrt{ }$ & $\sqrt{ }$ & & $\sqrt{ }$ \\
\hline & $\begin{array}{l}\text { "If the test is negative, can I stop } \\
\text { worrying?" }\end{array}$ & Performance & & & $\sqrt{ }$ & $\sqrt{ }$ \\
\hline & "What's wrong with me?" & Frequency & & & $\sqrt{ }$ & \\
\hline \multirow[t]{3}{*}{ Prognosis } & $\begin{array}{l}\text { "Will I be better off knowing how long I } \\
\text { have to live?" }\end{array}$ & Utility & $\sqrt{ }$ & $\sqrt{ }$ & & $\sqrt{ }$ \\
\hline & "How sure are you that I am at low risk?" & Performance & $\sqrt{++}$ & $\sqrt{ }$ & & $\sqrt{ }$ \\
\hline & "What is going to happen to me?" & Frequency & $\sqrt{++}$ & $\sqrt{ }$ & & \\
\hline \multirow[t]{3}{*}{ Harm (Accidental) } & "Will this treatment cause cancer?" & Utility & $\sqrt{ }$ & $\sqrt{ }$ & & $\sqrt{ }$ \\
\hline & $\begin{array}{l}\text { "Am I at low risk for bleeding from this } \\
\text { treatment?" }\end{array}$ & \begin{tabular}{|l|} 
Performance \\
\end{tabular} & $\sqrt{+}$ & $\sqrt{ }$ & & $\sqrt{ }$ \\
\hline & $\begin{array}{l}\text { "How often do patients who take this } \\
\text { medicine get depressed?" }\end{array}$ & Frequency & $\sqrt{+}$ & $\sqrt{ }$ & & \\
\hline \multirow[t]{3}{*}{ Harm (Incidental) } & "Was it my smoking?" & Utility & & $\sqrt{ }$ & & $\sqrt{ }$ \\
\hline & $\begin{array}{l}\text { "How can I know if I will get liver disease } \\
\text { from drinking?" }\end{array}$ & Performance & & $\sqrt{ }$ & & $\sqrt{ }$ \\
\hline & "Does everyone who smokes get cancer?" & Frequency & & $\sqrt{ }$ & & \\
\hline
\end{tabular}

${ }^{*} \mathrm{R}=\mathrm{RCT} ; \mathrm{Co}=$ cohort; $\mathrm{CS}$ = cross sectional design; $\mathrm{CC}$ = case control + Treatment arm only ++ Control arm only

Additionally, by prescribing the systematic comparison of the PICO elements of the practice question to the corresponding elements of the research as performed and by recognizing such differences between research and practice as potential sources of systematic error, the Road Map is consistent with the emerging framework of comparative effectiveness research [42]. The broad range of study designs recognized by the Road Map as potentially applicable to specific questions further strengthens this alignment.

Within the SIMPLE model, the Road Map subsumes the use of the concepts, tools and products of what is otherwise known as "evidence-based medicine" within a higher order domain of constructed action [16]. It adheres to a social constructivist epistemology for which powerful precedents exist within the framework of education $[43,44]$. Earlier models of evidence-based practice lacked a consistently elaborated epistemological foundation, rendering both critique and defense problematical $[38,44,45]$. The explicit nature of the SIMPLE model in this respect enables it to address both empirical observation, experience and evolving concepts of knowledge and science. As a result, the model opens the door to enrichment through a broad range of concepts and disciplines not otherwise available to a context bounded by clinical epidemiology.

\section{Limitations and forward perspectives}

The Road Map does not itself solve the dilemma of applying information from clinical research, derived from study populations, to the care of individual patients. However, we perceive the SIMPLE model to be more individual patient-centered than is standard EBM by virtue of the explicit primacy of the relational, interpretive process over decision-making [14]. It also addresses a broader range of patient concerns and potentially enhances the value of their consideration via potentially relevant research.

Limitations of the SIMPLE model include perceived complexity and lack of empirical validation with respect to educational outcomes. We propose that the complexity of the model ultimately is inherent within today's current practice. That is, the model does not introduce complexity, but rather seeks a framework within which the challenges of practice may be recognized and evaluated. Such a framework, in turn, makes possible orderly simplifications of presentation conforming to learning needs at different levels of expertise without loss of rigor and consistency. The second limitation is one that we take seriously. A potential strength of the SIMPLE model and the Road Map as a guide to curricular and instructional development, is that it corresponds to a concomitantly developed assessment instrument [15]. Development and empirical testing of curricular and instructional approaches constitutes a major priority of the model effort.

The SIMPLE model harnesses concepts developed within narrative medicine for the purpose of creating a bridge between the relational and interpretive process described by Epstein and others [18] and the fruits of clinical research. It does not itself subsume or attempt to completely elaborate the principles of narrative medicine. Similarly, the Road Map component of the SIMPLE 
model, presented in this article, is not itself a description or elaboration of narrative medicine. Rather it is distinguished by the fact that its format is coherent and compatible with the narrative dimension in a fashion not true of previous models of EBM. The cognitive processes involved in assimilation and integration of research information into healthcare relationships and decision-making requires further illumination. We believe the PACT tool, as described in Part 1 of this series [14], may facilitate this process. We perceive the SIMPLE model to resonate importantly with evolving concepts of the clinical relationship and decision-making [46,47] and consider the integration of the goals and objectives of EBM with those of narrative medicine to constitute an important frontier in the process of maximizing the value of healthcare in our time.

Finally, the model, as elaborated here, addresses only one class of information relevant to 'information literacy' in clinical practice. The emerging importance to clinical practice of a different class of information drawn from electronic health records and related sources [48] coheres with the content of the 'apply' phase of information literacy. The SIMPLE model allows for consideration of information from such sources in a fashion not mediated through direct consideration of clinical research information. It does not itself offer a systematic approach to collecting and analyzing such information. Information from research not easily classifiable within the categories of clinical action defined within the SIMPLE model contributes to the process through which practitioners formulate their assessments and recommendations and patients receive and interpret them. The SIMPLE model acknowledges the importance of such inputs, but does not attempt to address their systematic pursuit, evaluation and application.

\section{Conclusion}

The SIMPLE model and Road Map offer a framework for curricular approaches that address the process through which clinical actions are constructed, problems are defined, questions are posed and researched and information is assimilated into decisions and choices. Although not yet rigorously empirically validated, the model was developed from a measurement driven assessment project on practice-based learning and improvement. Its starting point lies in the appropriate delineation of the clinical problem as constructed in the course of a clinical relationship. The Road Map facilitates the extension of that process into the domain of outcomes based clinical research in a systematic and more comprehensive way than do existing models of evidencebased practice. Validated curricular and instructional approaches corresponding to the model and their empirical evaluation, are required and are in the process of development.

\section{Acknowledgments}

The authors would like to acknowledge Dr. Suzanne Bentley, who contributed the case material on the patient with atrial fibrillation while serving as chief resident in emergency medicine at Mount Sinai School of Medicine in New York City and Dr. Valdenia Pereira de Souza serving as chief of coronary care unit at Hospital de Clínicas the Niterói in Rio de Janeiro, who contributed the problem involving the use of the CHADAS score used in this paper.

\section{Conflicts of Interest}

The authors declare that they have no conflict of interest.

\section{References}

[1] Guyatt, G.H. (1991). Evidence-Based Medicine (Editorial) American College of Physicians Journal Club. Annals of Internal Medicine 114 (Supplement 2) A-16.

[2] Evidence-Based Medicine Working Group. (1992). Evidence-based medicine: A new approach to teaching the practice of medicine. Journal of the American Medical Association 268 (17) 2420-2425.

[3] Haynes, R.B., McKibbon, K.A., Walker, C.J., Mousseau, J., Baker, L.M., Fitzgerald, D., Guyatt, G. \& Norman, G.R. (1985). Computer searching of the medical literature. An evaluation of MEDLINE searching systems. Annals of Internal Medicine 103 (5) 812-816.

[4] Feinstein, A.R. (1968). Clinical epidemiology I. The populational experiments of nature and of main in human illness. Annals of Internal Medicine 69, 807-820.

[5] Sackett, D. (1981). How to read clinical journals: I. Why to read them and how to start reading them critically. Canadian Medical Association Journal 124, 555-558.

[6] Feinstein, A.R. \& Horwitz, R.I. (1997). Problems in the "Evidence" of "Evidence-based Medicine" American Journal of Medicine 103, 529-535.

[7] Wyer, P.C. \& Silva, S.A. (2009). Where Is The Wisdom: I. A Conceptual History of Evidence Based Medicine. Journal of Evaluation in Clinical Practice 15, 891-898.

[8] Sestini, P. (2010). Epistemology and ethics of evidence-based medicine: putting goal-setting in the right place. Journal of Evaluation in Clinical Practice 16, 301305.

[9] Dawes, M., Summerskill, W., Glasziou, P., et al. (2005). Sicily statement on evidence-based practice. BMC Medical Education 5 (1) 1.

[10] Kingsley, K.V. \& Kingsley, K. (2009). A case study for teaching information literacy skills. BMC Medical Education 9, 7.

[11] Presidential Committee on Information Literacy. Final Report.1989.

http://www.ala.org/ala/mgrps/divs/acrl/publications/whitep apers/presidential.cfm. Last accessed 20 November 2011. 
[12] Elwyn, G., Rosenberg, W., Edwards, A., Chatham, W., Jones, K., Matthews, S. \& Macbeth, F. (2000). Diaries of evidence-based tutors: beyond numbers needed to teach'. Journal of Evaluation in Clinical Practice 6, 149154.

[13] Wyer, P.C., Naqvi, Z., Dayan, P.S., Celentano, J.J., Eskin, B. \& Graham, M.J. (2009). Do workshops in evidence-based practice equip participants to identify and answer questions requiring consideration of clinical research? A diagnostic skill assessment. Advances in Health Sciences Education, Theory and Practice 14 (4) 515-533.

[14] Silva, S.A., Charon, R. \& Wyer, P.C. (2011). The marriage of evidence and narrative: scientific nurturance within clinical practice. Journal of Evaluation in Clinical Practice 17, 585-593.

[15] Chatterji, M., Graham, M.J. \& Wyer, P.C. (2009). Mapping Cognitive Overlaps between Practice-Based Learning and Improvement and Evidence-based Medicine: An Operational Definition for Assessing Resident Physician Competence. Journal of Graduate Medical Education 1, 287-298.

[16] Epstein, R.M. \& Peters, E. (2009). Beyond Information: Exploring Patient's Preferences. Journal of the American Medical Association 302, 195-197.

[17] Guyatt, G., Cook, D., Devereaux, P.J., Meade, M. \& Straus, S. (2002). Therapy. In: Users' Guides to the Medical Literature: A Manual for Evidence-Based Clinical Practice. (Guyatt, G. \& Rennie, D. eds.) pp. 55-79. Chicago: AMA Press.

[18] Sackett, D.L. \& Haynes, R.B. (2002).The architecture of diagnostic research. British Medical Journal 324 (7336) 539-541.

[19] Guyatt, G.H., Oxman, A.D., Vist, G.E., Kunz, R., Falck-Yttery, Y., Alonso-Coello, P., Schünemann, H.J. \& GRADE Working Group. (2008). GRADE: an emerging consensus on rating quality of evidence and strength of recommendations. British Medical Journal 336, 924-926.

[20] Green, R.C., Roberts, J.S., Cupples, L.A., Relkin, N.R., Whitehouse, P.J., Brown, T., Eckert, S.L., Butson, M., Sadovnick, A.D., Quaid, K.A., Chen, C., CookDeegan, R., Farrer, L.A. \& REVEAL Study Group. (2009). Disclosure of APOE Genotype for Risk of Alzheimer's Disease. New England Journal of Medicine 361, 245-254.

[21] Snyderman, R. \& Yoediono, Z. (2008). Prospective Health Care and the Role of Academic Medicine: Lead, Follow, or Get Out of the Way. Academic Medicine 83, 707-714.

[22] Leor, J., Rotstein, Z., Vared, Z., Kaplinsky, E., Truman, S. \& Eldar, M. (1994). Absence of tachycardia during tilt test predicts failure of b-blocker therapy in patients with neurocardiogenic syncope. American Heart Journal 127, 1539-1543.

[23] The NINDS t-PA Stroke Study Group. (1997). Intracerebral Hemorrhage After Intravenous t-PA Therapy for Ischemic Stroke. Stroke 28, 2109-2118.

[24] Richardson, W.S., Wilson, M.C., Guyatt, G.H., Cook, D.J. \& Nishikawa, J. (1999). Users' guides to the medical literature: XV. How to use an article about disease probability for differential diagnosis. Evidence-Based
Medicine Working Group. Journal of the American Medical Association 281 (13) 1214-1219.

[25] Stiell, I.G., Clement, C.M., Perry, J.J., Vallancourt, C., Symington, C., Dickinson, G., Birnie, D. \& Green, M.S. (2010). Association of the Ottawa Aggressive Protocol with rapid discharge of emergency department patients with recent-onset atrial fibrillation or flutter. Canadian Journal of Emergency Medicine 12, 181-191.

[26] Eddy, D.M. (1990). Practice policies: Where do they come from? Journal of the American Medical Association 263, 1266-1275.

[27] Chatterji, M. (2003). Designing and Using Tools for Educational Assessment. Boston, MA: Allyn \& Bacon.

[28] McKibbon, A. \& Wyer, P. (2008). Finding the Evidence. In: Users' Guides to the Medical Literature. (Guyatt, G., Rennie, D., Meade, M.O. \& Cook, D.J., eds.) pp. 29-58. New York: McGraw-Hill.

[29] Guyatt, G., Rennie, D., Meade, M.O. \& Cook, D.J. (2008). Users' Guides to the Medical Literature: A Manual for Evidence Based Clinical Practice. 2nd edn. New York: McGraw-Hill.

[30] Richardson, W.S., Wilson, M.C., Keitz, S.A. \& Wyer, P.C. (2008). Tips for teachers of evidence-based medicine: making sense of diagnostic test results using likelihood ratios. Journal of General Internal Medicine 23 (1) 87-92. [31] Porter, M.E. (2010). What is value in health care? New England Journal of Medicine 366, 2477-2481.

[32] Chou, R., Aronson, N., Atkins, D., Ismaila, A.L., Santaguida, P., Smith, D.H., Whitlock, E., Wilt, T.J. \& Moher, D. (2010). AHRQ Series Paper 4: Assessing harms when comparing medical interventions: AHRQ and the Effective Health-Care Program. Journal of Clinical Epidemiology 63, 502-512.

[33] Goyal, R.K., Charon, R., Lekas, H., Fullilove, M.T., Devlin, M.J., Falzon, L. \& Wyer, P.C. (2008). 'A local habitation and a name': how narrative evidence-based medicine transforms the translational research paradigm. Journal of Evaluation in Clinical Practice 14, 732-741.

[34] Letelier, L.M., Udal, K., Ena, J., Weaver, B. \& Guyatt, G.H. (2003). Effectiveness of amiodarone for conversion of atrial fibrillation to sinus rhythm. Archives of Internal Medicine 163, 777-785.

[35] Nichol, G., McAlister, F., Pham, B., Laupacis, A., Shea, B., Green, M., Tang, A. \& Wells, G. (2002). Metaanalysis of randomised controlled trials of the effectiveness of antiarrhythmic agents at promoting sinus rhythm in patients with atrial fibrillation. Heart 87, 535-543.

[36] Keogh, C., Wallace, E., Dillon, C., Dimitrov, B.D. \& Fahey, T. (2011). Validation of the CHADS2 clinical prediction rule to predict ischaemic stroke: A systematic review and meta-analysis. Journal of Thrombosis and Haemostasis 106 (3) 528-538.

[37] Ortiz, M.R., Romo, E., Mesa, D., Delgado, M., Anquita, M., Castillo, J.C., Arizón.J.M. \& Suárez De Lezo, J. (2010). Oral Anticoagulation in Nonvalvular Atrial Fibrillation in Clinical Practice: Impact of CHADS 2 Score on Outcome. Cardiology 115, 200-204.

[38] Charles, C., Gafni, A. \& Freeman, E. (2011). The evidence-based medicine model of clinical practice: scientific teaching or belief-based preaching? Journal of Evaluation in Clinical Practice 17 (4) 597-605. 
[39] Guyatt, G.H., Oxman, A., Kunz, R., Woodcock, J., Brozek, J., Helfand, M., Alonso-Coello, P., Falck-Ytter, Y., Jaeschke, R., Vist G., Akl, E.A., Post, P.N., Norris, S., Meerpohl, J., Shukla, V.K., Nasser, M., Schünemann, H.J. \& GRADE Working Group. (2011). GRADE guidelines: 8. Rating the quality of evidence: indirectness. Journal of Clinical Epidemiology 64 (12) 1303-1310.

[40] Guyatt, G.H., Oxman, A.D., Kunz, R., Vist, G.E., Falck-Ytter, Y., Schünemann, H.J. \& GRADE Working Group. (2008). What is "quality of evidence" and why is it important to clinicians? British Medical Journal 336 (7651) 995-998.

[41] Eddy, D.M. (2005). Evidence-based medicine: A unified approach. Health Affairs 24, 9-17.

[42] Sox, H.C. (2009). Comparative effectiveness research: A report from the Institute of Medicine. Annals of Internal Medicine 151, 203-205.

[43] Freire, P. (1974). Education for Critical Consciousness. New York: Continuum.

[44] Silva, S.A. \& Wyer, P.C. (2009). Where is the wisdom? II - Evidence-based medicine and the epistemological crisis in clinical medicine. Exposition and commentary on Djulbegovic, B., Guyatt, G. H. \& Ashcroft, R. E. (2009). Cancer Control 16, 158-168. Journal of Evaluation in Clinical Practice 15, 899-906.

[45] Djulbegovic, B., Guyatt, G.H. \& Ashcroft, R.E. (2009). Epistemologic Inquiries in Evidence-Based Medicine. Cancer Control 16, 158-168.

[46] Beach, M.C. \& Inui, T. (2006). Relationship-centered Care: A Constructive Reframing. Journal of General Internal Medicine 21 (Supplement 1) S3-S8.

[47] O'Grady, L. \& Jadad, A. (2010). Shifting from shared to collaborative decision making: a change in thinking and doing. Journal of Participatory Medicine 2, e13.

[48] Frankovich, J., Longhurst, C.A. \& Sutherland, S.M. (2011). Evidence-Based Medicine in the EMR Era. New England Journal of Medicine 365 (19) 1758-1759. 